Esta obra forma parte del acervo de la Biblioteca Jurídica Virtual del Instituto de Investigaciones Jurídicas de la UNAM

www.juridicas.unam. $m x$

\title{
Derecho de réplica y facultad reglamentaria del IFE
}

\author{
Ernesto Villanueva* \\ Karla Valenzuela**
}

* Investigador en el Instituto de Investigaciones Jurídicas de la UNAM donde coordina el área de Derecho de la información.

** Asistente de investigación adscrita al área de Derecho de la información del Instituto de Investigaciones Jurídicas de la UNAM.

D. R. () 2012. Universidad Nacional Autónoma de México-Instituto de Investigaciones Jurídicas. Revista Mexicana de Derecho Electoral, núm. 2, julio-diciembre de 2012, pp. 345-365, 
La reforma constitucional en materia electoral publicada en el Diario Oficial de la Federación el 13 de noviembre de 2007 introdujo una adición al artículo 6o. creando la figura del derecho de réplica, también conocido como derecho de rectificación o respuesta. En el artículo 60. constitucional ahora se establece en su primer párrafo que: "El derecho de réplica será ejercido en los términos dispuestos por la ley". De entrada, desde nuestro punto de vista es adecuada la terminología utilizada como "derecho de réplica" y no rectificación o respuesta, como se ha reconocido en distintos ordenamientos del derecho extranjero. Existen, por supuesto, razones para que se manifieste nuestra adhesión al vocablo definido por el poder reformador de la Constitución.

En efecto, si se analizan los vocablos "respuesta", "rectificación" o "réplica" conforme al Diccionario de la Lengua Española de la Real Academia, se puede observar que rectificación incluye la posibilidad de "contradecir a alguien en lo que ha dicho, por considerarlo erróneo", pero también que el periodista o comunicador modifique "la propia opinión que se ha expuesto antes". Por su parte, el vocablo "respuesta" admite varias definiciones, entre ellas la "satisfacción a una pregunta, duda o dificultad" o bien la "réplica, refutación o contradicción de lo que alguien dice". La noción de "réplica" es más precisa para delimitar esta figura jurídica, pues se define como "expresión, argumento o discurso con que se replica”. En el ámbito jurídico, sostiene el mismo diccionario, significa el "segundo escrito del actor en el juicio de mayor cuantía para impugnar la contestación y la reconvención, si la hubo, y fijar los puntos litigiosos".

Por otro lado, de la lectura atenta del enunciado normativo del citado texto constitucional se advierte expresamente que el derecho humano en comento está sujeto para su desarrollo a lo que se denomina el principio de reserva de ley, anotación fundamental por cuanto hace al análisis de las atribuciones del Instituto Federal Electoral que veremos más adelante. El derecho de réplica significa la prerrogativa que tiene toda persona para que se inserte su declaración cuando haya sido mencionada en una nota periodística, siempre que esa información sea inexacta en su perjuicio o afecte su derecho al honor, a la vida privada o a la propia imagen.

Esta institución jurídica es de vieja data en el derecho comparado. Distintos autores coinciden en que el origen de esta figura se ubica en una iniciativa de ley presentada por el diputado francés J. A. Dulaure, 
en 1795, que finalmente no prosperó, para el "establecimiento de la libertad de prensa y la represión de los abusos".

En 1822, en Francia, con el propósito de salvar a la monarquía de la asidua crítica de la prensa:

En virtud de una enmienda presentada a la Ley de Prensa por el diputado francés, Mestadier, fue incluido en el art. 11 de la Ley del 25 de marzo. Según este artículo se concedía este derecho a toda persona nombrada en los periódicos, para que ejercida la facultad de rectificación fuese insertada con carácter gratuito, en el número más próximo, y en el plazo de tres días, la nota rectificadora que podría ser el doble de la que contestaba. ${ }^{2}$

Más tarde, en este país se establecería el derecho de réplica en la Ley del 29 de julio de 1881 (artículos 13 y 13-1) y de ahí en buena parte de las democracias se ha legislado con mayor o menor profundidad.

El derecho de réplica fue combatido severamente en sus inicios en el hemisferio americano por las asociaciones de propietarios de medios quienes consideraban que esta prerrogativa restringía o limitaba ilegítimamente el ejercicio de la libertad de expresión. ${ }^{3}$ Hoy ha sido aceptado por la doctrina que el derecho de réplica es un límite a la libertad de expresión, pero una garantía para el derecho a la información. ${ }^{4}$ Por esta razón la postura de varios empresarios de medios ha sido matizada parcialmente hoy en día por el replanteamiento del papel de los medios, habida cuenta que al igual que muchas instituciones sociales pasan por un periodo de reconstrucción de su credibilidad social. No menos importante es el desarrollo cultural de la sociedad que se ha vuelto gradualmente más exigente de lo que recibe de los medios. El fortalecimiento del derecho a la información ha aumentado también su rol en la sociedad, habida cuenta que sólo con

1 Así, por ejemplo, Islas L., Jorge, "El derecho de réplica y la vida privada”, en Jiménez, Armando Alfonso (coord.), Responsabilidad social, autorregulación y legislación en radio y televisión, México, UNAM, 2002, p. 78; Ballester, Eliel C., Derecho de respuesta. Réplica. Rectificación, Buenos Aires, Astrea, 1987, p. 1.

2 Molinero, César, Teoría y fuentes del derecho de la información, 2a ed., Barcelona, EUB, 1995, pp. 203.

3 Villalobos, Quirós, Enrique, “El derecho de rectificación o respuesta”, en Villanueva, Ernesto (coord.), Diccionario de derecho de la información, México, Porrúa. 207.

${ }^{4}$ Uprimny, Rodrigo et al., Libertad de prensa y derechos fundamentales, Bogotá, Andiarios-Fundación Konrad Adenauer, 2006 p. 21. 
ciudadanos informados tiene sentido la idea de ciudadanía en un Estado democrático de derecho.

De entrada, habría que decir que el derecho de réplica juega un papel de importancia capital entre los medios y el público, toda vez que su propia naturaleza hace que juegue un papel preventivo y eficaz que obvie en un primer momento un proceso judicial para reparar la lesión del honor, la vida privada o la propia imagen con motivo de imputaciones formuladas a través de un medio de comunicación. Así, hemos sostenido en otras oportunidades que este derecho representa el primer instrumento con que cuenta el ciudadano para acceder a los medios de comunicación a fin de hacer valer sus puntos de vista sobre hechos que lesionen sus derechos fundamentales.

De esta forma, es posible extraer algunas consideraciones sobre los objetivos de este singular derecho, entre las que destacan las siguientes: a) constituye una vía inmediata, de carácter extrajudicial, que habilita al particular para defender su honor, vida privada o imagen afectadas por información inexacta, equivocada o injuriosa, mediante la difusión de las precisiones o correcciones pertinentes, en el medio en que se originó la controversia; $b$ ) representa un vehículo de comunicación entre emisores y receptores, que fomenta la veracidad en la información que transmiten los medios de comunicación a la opinión pública; $c$ ) ofrece a la sociedad civil distintas posturas y puntos de vista sobre hechos controvertidos, lo que le brinda mayores elementos de juicio sobre temáticas de interés general. Uno de los puntos medulares es cómo regular el derecho de réplica.

En suma, como sostiene Héctor Gros Espiell:

En su dimensión individual, el derecho de rectificación o respuesta garantiza al afectado por una información inexacta o agraviante la posibilidad de expresar sus puntos de vista y su pensamiento respecto de esa información emitida en su perjuicio. En su dimensión social, la rectificación o respuesta permite a cada uno de los integrantes de la comunidad recibir una nueva información que contradiga o discrepe con otra anterior, inexacta o agraviante. ${ }^{5}$

5 Opinión separada del juez Héctor Gros en la opinión consultiva OC-7/86, del 29 de agosto de 1986 de la Corte Interamericana de Derechos Humanos. 
En la misma tesitura, el Tribunal Constitucional español reconoce que el derecho de réplica cumple una doble función como característica de libertad individual y como "garantía institucional para la existencia de una opinión pública libre indisolublemente unida al pluralismo político dentro de un Estado democrático". 6

Es muy importante que esta institución pueda cumplir su propósito normativo sin afectar la libertad de expresión, pero también sin dejar de considerar todos los elementos requeridos para ser eficaz. El dictamen de la reforma constitucional en México hecho por el Senado de la República en primera y segunda lectura se limita sólo a destacar la importancia de este derecho, pero es de lamentar que sea omiso en las consideraciones que implica la inserción de esta institución en el artículo 6o. de la Constitución, el desconocimiento de las normas que ya lo regulan en México - así sea de manera poco afortunada- y algunas líneas generales o elementos de cómo debe ser desarrollado este derecho en la legislación secundaria. El dictamen, a la letra dice:

Finalmente, en lo que hace a los cambios aprobados por estas Comisiones Unidas respecto del contenido de la Iniciativa bajo dictamen, es necesario precisar que han resuelto aprobar la propuesta del Grupo de Trabajo para adicionar el primer párrafo del Artículo $6^{\circ}$ de la Constitución a fin de colmar un vacío que hasta la fecha subsiste en nuestro orden jurídico. Nos referimos al derecho de réplica con que toda persona debe contar frente a los medios de comunicación social. La única ley en que ese derecho se encuentra consagrado, la Ley de Imprenta, antecede a la Constitución de Querétaro de 1917 y su inoperancia se constata desde hace décadas. Al introducir en la Constitución el derecho de réplica será posible que el Congreso de la Unión actualice de manera integral el marco jurídico que tutela y protege el derecho a la información, tal y como fue la intención del Constituyente Permanente con la reforma al propio artículo $6^{\circ}$ en comento en reforma promulgada en fechas recientes.

Sobra decir que esta institución jurídica no nace a partir de su reconocimiento constitucional en 2007. En México, el derecho de réplica se regula ya desde principios del siglo XX. En efecto, el artículo 27 de la Ley de Imprenta de 1917, a la letra dice:

6 STC 40/92. 
Los periódicos tendrán la obligación de publicar gratuitamente las rectificaciones o respuestas que las autoridades, empleados o particulares quieran dar a las alusiones que se les hagan en artículos, editoriales, párrafos, reportazgos o entrevistas, siempre que la respuesta se dé dentro de los ocho días siguientes a la publicación, que no sea mayor su extensión del triple del párrafo o artículo en que se contenga la alusión que se contesta, tratándose de autoridades, o del doble, tratándose de particulares; que no se usen injurias o expresiones contrarias al decoro del periodista, que no haya ataques a terceras personas y que no se cometa alguna infracción de la presente ley. Si la rectificación tuviere mayor extensión que la señalada, el periódico tendrá obligación de publicarla íntegra; pero cobrará el exceso al precio que fije en su tarifa de anuncios, cuyo pago se efectuará o asegurará previamente.

La publicación de la respuesta se hará en el mismo lugar y con la misma clase de letra y demás particularidades con que se hizo la publicación del artículo, párrafo o entrevista a que la rectificación o respuesta se refiere. La rectificación o respuesta se publicará al día siguiente de aquel en que se reciba, si se tratare de publicación diaria o en el número inmediato, si se tratare de otras publicaciones periódicas.

Si la respuesta o rectificación se recibiere cuando por estar ya arreglado el tiro no pudiere publicarse en los términos indicados se hará en el número siguiente. La infracción de esta disposición se castigará con una pena que no baje de un mes ni exceda de once, sin perjuicio de exigir al culpable la publicación correspondiente, aplicando, en caso de desobediencia, la pena del art. 904 del Código Penal para Distrito Federal.

Del análisis de este artículo se pueden hacer tres consideraciones, a saber: $a$ ) el acto de otorgar el derecho de réplica a toda persona aludida en cualquier comentario editorial, artículo o nota informativa, como lo hace el artículo 27, restringe el ámbito preferente de las libertades de expresión e información, en la medida que toda nota informativa, comentario editorial, o ambos, que se refiera a una institución pública o a un particular sería sujeta de ser contrastada, en todos los casos y en las páginas del mismo periódico, por los puntos de vista de la persona aludida, sean o no de interés periodístico; $b$ ) aceptar ese amplio universo para ejercer el derecho de réplica puede ser lesivo también para el lector, quien en lugar de recibir información y opinión de interés público, sería sólo receptor de un interminable intercambio de juicios de valor, lo que desnaturalizaría la esencia del trabajo periodístico, y 
c) de igual forma, el derecho de crítica a la función pública — sin el cual quedarían sin sentido las libertades de expresión e informaciónse vería gravemente afectado por este ejercicio sin medida del derecho de alusión, que inhibiría el trabajo periodístico y fomentaría, por el contrario, las prácticas nocivas de la autocensura.

En materia electoral, el derecho de réplica también ha tenido vida jurídica. En efecto, el artículo 186, numeral 3, del Código Federal de Instituciones y Procedimientos Electorales de 1996 reconoce esta misma figura en comento, en los términos siguientes:

3. Los partidos políticos, las coaliciones y los candidatos, podrán ejercer el derecho de aclaración respecto de la información que presenten los medios de comunicación, cuando consideren que la misma ha deformado hechos o situaciones referentes a sus actividades o atributos personales.

Este derecho se ejercitará, sin perjuicio de aquellos correspondientes a las responsabilidades o al daño moral que se ocasionen en términos de la ley que regule la materia de imprenta y de las disposiciones civiles y penales aplicables.

Esta disposición en la práctica nunca fue eficaz por tratarse de una norma imperfecta, habida cuenta que el legislador omitió establecer una sanción a la conducta contraria a la establecida como debida por la ley.

De la misma manera, en materia de radio y televisión si bien no existe un derecho de réplica en la ley en la materia, aparece, empero, una referencia en el artículo 38 del Reglamento de la Ley Federal de Radio y Televisión, en materia de concesiones, permisos y contenidos de las transmisiones de radio y televisión, que dispone:

Toda persona, física o moral, podrá ejercitar el derecho de réplica cuando un material que sea difundido en cualquier programa de una estación de radio o televisión no cite la fuente de la cual extrajo la información y considere que los hechos que la aluden son falsos e injuriosos. Para hacer valer este derecho, el interesado presentará, por escrito y dentro de las cuarenta y ocho horas siguientes a la transmisión, la solicitud de aclaración pertinente ante la estación de radio o televisión correspondiente, la cual evaluará su procedencia, a efecto de hacer la aclaración. 
En caso que la estación de radiodifusión estime que la aclaración solicitada es improcedente, el interesado tendrá a salvo sus derechos para recurrir a las vías jurisdiccionales correspondientes.

De obtener el interesado resolución firme y favorable de la autoridad jurisdiccional, el concesionario o permisionario de radio o televisión transmitirá la aclaración correspondiente en los términos de la resolución.

El derecho de réplica podrá ser ejercido por el perjudicado aludido $y$, a falta de éste, por sus parientes en línea ascendente o descendente en primer grado.

En caso de que la estación de radiodifusión cite la fuente de la cual extrajo la información, y ésta haga la aclaración correspondiente, el aludido podrá ejercitar ante el concesionario o permisionario de radio o televisión el derecho consagrado en este artículo.

Es de hacer notar que el derecho de réplica en radio y televisión ofrece los siguientes inconvenientes tal y como está redactado en el Reglamento de referencia:

a) Es un principio jurídico universalmente aceptado que los derechos deben ser creados por ley y, en su caso, desarrollados por reglamento. La figura del reglamento lo que hace es desarrollar la ley sin alterarla ni modificarla; es decir, sin acotar ni maximizar su alcance. ${ }^{7}$ De ahí, por tanto, existe un problema de técnica legislativa que hace endeble el bien jurídico protegido; $b$ ) el artículo 38 del reglamento de referencia reclama la existencia de tres requisitos para que se pueda considerar la eventual réplica: la ausencia de fuente, la falsedad y la injuria; es decir, el ánimo de ofender. La inclusión de estos tres requisitos procedimentales, a diferencia de la laxitud de lo que sucede con la Ley de Imprenta que tampoco es correcto, restringe el ejercicio de este derecho, en virtud de que no basta la falsedad o las frases injuriosas por sí mismas, sino que además se introduce un nuevo elemento que no es reconocido por el derecho extranjero, relativo a citar o no la fuente. ${ }^{8}$ Estas características hacen de suyo complicado el ejercicio de

7 Cfr. Amparo directo 33/2002. Luis Humberto Escalante Enríquez. 19 de septiembre de 2002.

8 Cabe apuntar aquí que la inclusión de la cita de la fuente de información como requisito para ejercer el derecho de réplica lesiona, por otro lado, el derecho al secreto profesional del periodista reconocido en la ley del mismo nombre en el Distrito Federal y en 
este derecho, y c) la redacción del contenido normativo del artículo es propio de lo que se denomina también como una norma imperfecta, habida cuenta que carece por su propia naturaleza reglamentaria de sanciones para generar incentivos de cumplimiento. De esta suerte, el derecho de réplica es sólo una formalidad sujeta a la buena voluntad del concesionario o permisionario de radio y/o televisión, quien decide libremente si es procedente ese derecho o no lo es.

Hay que recordar del mismo modo que el derecho de réplica forma parte también del derecho interno derivado del mandato previsto en el artículo 14.2.2 de la Convención Americana de Derechos Humanos, que textualmente dispone:

1. Toda persona afectada por informaciones inexactas o agraviantes emitidas en su perjuicio a través de medios de difusión legalmente reglamentados y que se dirijan al público en general, tiene derecho a efectuar por el mismo órgano de difusión su rectificación o respuesta en las condiciones que establezca la ley.

Sobra decir que la Convención Americana de Derechos Humanos es un instrumento jurídico internacional suscrito por México con las debidas formalidades. Baste apuntar que fue aprobado por el Senado de la República ${ }^{9}$ y más tarde se publicó el decreto de promulgación. ${ }^{10}$

El artículo 133 de la Constitución Política de los Estados Unidos Mexicanos establece en forma clara que:

Esta Constitución, las leyes del Congreso de la Unión que emanen de ella y todos los tratados que estén de acuerdo con la misma, celebrados y que se celebren por el Presidente de la República, con aprobación del Senado, serán la Ley Suprema de toda la Unión. Los jueces de cada Estado se arre-

el Código Penal Federal. Es inadecuado que la invocación del secreto profesional de los periodistas esté relacionado con el ejercicio del derecho de réplica, habida cuenta que se trata de derechos distintos, no contrapuestos y que deben ser armonizados en el sistema jurídico. Por esta razón, además, los instrumentos internacionales no hacen referencia alguna a las fuentes para permitir o no el ejercicio del derecho de réplica.

9 La aprobación se publicó en el Diario Oficial de la Federación el 18 de diciembre de 1980.

${ }^{10}$ La promulgación se publicó en el Diario Oficial de la Federación el 7 de mayo de 1981, a partir de entonces comenzó su vigencia en México. 
glarán a dicha Constitución, leyes y tratados, a pesar de las disposiciones en contrario que pueda haber en las Constituciones o leyes de los estados.

El gran problema a propósito del derecho de réplica reside en cómo definir las formas de hacer operativo este derecho. No hay consensos o voces unívocas sobre cómo reglamentar el derecho de réplica en nuestro país. Los escasos intentos han sido cuestionados por buenas o malas razones.

En efecto, el 13 de diciembre de 2007, el senador Alejandro Zapata presentó una iniciativa de ley en materia de derecho de réplica. El propósito pudo haber sido atendible y entendible, pero el contenido de la iniciativa de ley fue poco afortunado. Peor aún, se trata de una rendija donde mecanismos de censura indirecta hubieran podido tener cabida. En esta iniciativa el derecho de réplica no comprende los tres requisitos básicos para que ese supuesto pueda hacerse valer: a) una nota informativa inexacta $y /$ o agraviante; $b$ ) un medio donde se difunda, $y c$ ) un perjuicio a una persona específica. Este último requisito, el senador Zapata lo deja fuera en el artículo 5o. de su iniciativa y con ello abre la puerta a un indiscriminado derecho de acceso a opinar de todo y de todos en los medios. Ello podría poner en riesgo el libre flujo informativo y provocar una parálisis del propósito que anima a las libertades de informar, honrar el derecho a saber.

De la misma forma, para el senador Zapata la excepción para ejercer el derecho de réplica procede sólo cuando haya críticas "objetivas" de actividades públicas del aludido. Es un principio universalmente aceptado que la crítica y la opinión no deben ser calificadas de falsas o verdaderas, razón por la cual la subjetividad es propia de su naturaleza, a diferencia de la información que sí debe tener dosis sustantivas de veracidad, de acuerdo a la Suprema Corte de Justicia de la Nación. ${ }^{11}$ La iniciativa del senador Zapata no tuvo éxito y quedó atrapada en comisiones dentro del Senado de la República.

Pocos meses después, el 8 de abril de 2009, los diputados José Antonio Díaz, Dora Alicia Martínez Valero y Rocío Morgan Franco, presentaron otra iniciativa de ley sobre la misma materia. A diferencia de la elaborada por el senador Zapata, esta iniciativa presentaba una mejor estructura y no ofrecía mayores problemas a las libertades informativas.

11 Amparo en revisión 2099/99. Evangelina Vázquez Curiel. 7 de marzo de 2000. 
Para evitar el ejercicio abusivo de este derecho, la iniciativa de referencia establece como requisitos para ejercer este derecho: $a$ ) que se trate de información que expresamente aluda a una persona determinada; $b$ ) que se trate de información inexacta o falsa y que su divulgación pueda afectar el derecho al honor, a la vida privada o a la propia imagen. Como se puede advertir, en esta iniciativa se requiere cumplir necesariamente con dos requisitos, que haya información inexacta y que además sea agraviante para una persona específica. En otras legislaciones el "y" está redactado como "o", lo que le da un sentido distinto. Para el caso de México esta iniciativa puede ser un buen punto de partida de lo que hasta este momento se ha presentado para su estudio en el Congreso de la Unión.

Ante la posibilidad de que se reglamentara el derecho de réplica, el Partido Verde, a través del senador Javier Orozco, propuso que este derecho fuera garantizado por los propios medios a través de un código de ética y un defensor de la audiencia. Nadie duda de la importancia de que los medios adopten un sistema de autorregulación, particularmente los electrónicos por su basta influencia social. Es importante precisar también que los códigos de ética no sustituyen a la ley, sino que la complementan en el ejercicio de su libertad con responsabilidad social.

La réplica es un derecho humano que no puede ser garantizado por la buena voluntad de los medios (que casi nunca ha existido) sino por la ley con mecanismos adecuados que garanticen su eficacia. De no ser así, no tendría sentido que el derecho de réplica haya sido reconocido expresamente en la Constitución.

En este contexto es importante que el comité de diseño normativo de la ley del derecho de réplica, considere al menos los siguientes elementos:

1) Titular del derecho. El derecho debe incluir sin distinción a toda persona, sin importar si se trata de una persona física o jurídica. Así lo establecen las distintas convenciones al referirse a la palabra "persona”. La regla es clara: donde no distingue el legislador, no lo debe hacer el intérprete. A mayor abundamiento, esta postura ha sido interpretada por la clásica resolución (74) 26 sobre derecho de réplica adoptada por el Comité de Ministros del Consejo de Europa el 2 de julio de 1974 de cuyas posturas abrevó tiempo después la Corte Interamericana de Derechos Humanos. 
2) Informaciones y opiniones. Desde nuestro punto de vista el derecho de réplica debe proceder como regla general en el caso de informaciones difundidas en perjuicio de quien puede ejercer el derecho de réplica, como dispone el artículo 14 de la Convención Americana de Derechos Humanos y reiterado por la Corte Interamericana de Derechos Humanos en la opinión consultiva OC-7/86, del 29 de agosto de 1986 y que ha sido observada a través de resoluciones con carácter jurisprudencial en la región. ${ }^{12}$ De manera complementaria creemos, empero, que tratándose de opiniones basadas en hechos o datos incorrectos debe proceder también el derecho de réplica. De la misma forma, hay que considerar que la fotografía o la imagen constituyen una referencia a la persona, aunque a simple vista pareciera no contestable (pese a que aquélla pudiera afectar la intimidad o se haya obtenido contra la voluntad del implicado, en este caso operaría la acción judicial para resarcir el daño moral provocado); pero si la fotografía se edita y refleja una escena que nunca existió, es posible ejercer el derecho de réplica. La réplica no debería proceder en el caso de opiniones injuriosas por sí mismas, pues si bien es verdad que lastiman el derecho al honor, a la vida privada o a la propia imagen, la reparación debe buscarse a través de las herramientas legales que protegen la lesión de estos derechos. Evidentemente es inaceptable el derecho al insulto.

En el caso del Distrito Federal, la reparación del patrimonio moral se puede concretar a través de la Ley de Responsabilidad Civil para la Protección del Derecho a la Vida Privada, el Honor y la Propia Imagen en el Distrito Federal y en otros estados mediante la figura del daño moral o por la vía penal bajo los tipos penales de difamación y/o calumnias, aunque nuestra postura es que las reclamaciones por posibles ejercicios abusivos de la libertad de expresión y/o información se lleven a cabo por la normativa civil.

3) Extensión de la réplica. En la experiencia comparada no hay una respuesta unívoca sobre la extensión máxima de la información replicada. En algunos casos se establecen máximos de dos o tres veces el texto impugnado. Quizá sea posible mantener esa regla, pero dejando abierta la posibilidad para que la extensión pueda ampliarse de manera razonable cuando por la naturaleza de la información replicada no pueda ajustarse a la extensión habitual.

${ }_{12}$ Cfr. por ejemplo, la sentencia T-048/93 de la Corte Constitucional de Colombia. 
4) Características de la réplica. La réplica no debe limitarse a determinados medios, sino debe permitirse su ejercicio ante cualquier medio existente o por existir. Esta medida debe ser particularmente considerada si se determina adoptar una ley especial sobre la materia. Debe limitarse sólo a aclarar o responder los datos incompletos o falsos. De no ser así habría una serie de intercambio de puntos de vista que desnaturalizaría la naturaleza de este derecho y podría menoscabar el ejercicio de la libertad de expresión. Debe hacerse sin frases injuriosas contra quien se replica o contra un tercero. El principio es claro: no puede ejercerse un derecho humano mediante la lesión de los derechos de los demás. Debe ser difundida con características similares a la información controvertida.

Es entendible que debe primar el principio de proporcionalidad para generar un equilibrio entre la nota replicada y la réplica en la percepción del público y en la satisfacción del propósito del derecho. Y, por supuesto, debe hacerse sólo por quien tiene interés jurídico para invocar y ejercer este derecho. De no ser así, esos puntos de vista podrían entrar si así lo decide el editor del medio de comunicación en las cartas del lector o en buzón de opiniones, pero queda claro que no está obligado a difundir esas opiniones. Más todavía, en estos casos de opiniones de terceros el editor puede sintetizar su contenido y en la réplica debe difundirse en sus términos.

5) Prescripción del derecho. En la experiencia comparada no hay un plazo universal para que prescriba este derecho. Es lógico que por la propia naturaleza de esta figura jurídica que tiene en el sentido de oportunidad su eficacia y razón de ser debe ejercerse en el menor tiempo que sea razonablemente posible. En todo caso, debe realizarse un adecuado estudio para establecer una regla general y admitir excepciones razonables, tratándose de un derecho humano fundamental y tomando en cuenta que la persona perjudicada será la primera interesada en que su réplica sea difundida.

6) Sanciones. El rechazo injustificado de un medio para que una persona ejerza su derecho de réplica debe dar lugar a un juicio sumarísimo ante la autoridad competente que pueda aplicar sanciones y ordenar simultáneamente medidas cautelares para que este derecho sea eficaz. Hay que tener claro que la réplica del afectado no sustituye ni exime de las responsabilidades legales a que hubiere lugar en materia 
civil o penal, aunque sí pueden constituir atenuantes de responsabilidad a juicio del juzgador.

De 2007 a principios de 2011 no se han presentado iniciativas de leyes reglamentarias del derecho de réplica. No obstante, ahora, de cara al proceso electoral por la renovación de la Presidencia de la República en 2012 y debido a la fuerza creciente de los medios televisivos privados, el Instituto Federal Electoral ha enfrentado tensiones internas por el derecho de réplica. Ello, en principio, sería plausible en virtud de que la naturaleza colegiada del árbitro electoral anima las diferencias de percepción y de criterio sobre los más distintos rubros que son parte de su objeto normativo. Preocupa. No obstante, cuando la libre deliberación transita por senderos ajenos al sistema jurídico vigente invocando argumentos atendibles desde la perspectiva metajurídica, pero inadmisibles desde el derecho. En efecto, fue de lamentar que el IFE haya abrigado la percepción pública de que puede reglamentar o normar el derecho de réplica sin observar el procedimiento que la Constitución Política de los Estados Unidos Mexicanos establece para estos efectos.

Por esta razón, el derecho de réplica en materia electoral ha generado una breve pero intensa discusión sobre qué, cómo y quién debe regular este derecho humano fundamental reconocido por la Constitución.

Uno de los debates es si la réplica procede contra informaciones y opiniones o sólo por aquéllas. Desde nuestro punto de vista el derecho de réplica debe proceder como regla general en el caso de informaciones difundidas en perjuicio de quien puede ejercer dicho derecho, como dispone el artículo 14 de la Convención Americana de Derechos Humanos y reiterado por la Corte Interamericana de Derechos Humanos en la opinión consultiva OC-7/86, del 29 de agosto de 1986.

Por otra parte, este derecho ha sido objeto de discusión sobre el alcance de las atribuciones constitucionales y legales del IFE para emprender una empresa reglamentaria de este derecho humano, así haya sido bajo el eufemismo de que "no genera leyes, produce reglamentos en sintonía con aquellas y conforme a lo dispuesto en el artículo 118, inciso a) del Cofipe", según su comunicado de prensa 108. Conviene no perder de vista que es un principio jurídico universalmente aceptado que los derechos reconocidos por la Constitución sólo pueden ser reglamentados por una ley expedida por el Congreso de la Unión 
a diferencia de las prescripciones establecidas en la ley secundaria que pueden ser desarrolladas por un reglamento. En España, por ejemplo, es muy ilustrativo lo dispuesto por el artículo 53.1, que a la letra dice:

1. Los derechos y libertades reconocidos en el Capítulo segundo del presente Título vinculan a todos los poderes públicos. Sólo por ley, que en todo caso deberá respetar su contenido esencial, podrá regularse el ejercicio de tales derechos y libertades, que se tutelarán de acuerdo con lo previsto en el artículo 161, 1, a).

Se ha dicho ya que la figura del reglamento lo que hace es desarrollar la ley sin alterarla ni modificarla. De ahí, por tanto, que la idea del IFE de reglamentar el derecho de réplica tiene no sólo un impedimento constitucional sino lo encuentra también en el propio artículo 233, numeral 4, del Cofipe, que a la letra dice: "4. El derecho a que se refiere el párrafo anterior (de réplica) se ejercerá en la forma y términos que determine la ley de la materia”. En otras palabras, el IFE sólo puede reglamentar el citado derecho siempre y cuando previamente exista una ley. No tiene atribuciones, sin embargo, para llenar lagunas o vacíos legales por más que tenga toda la razón en deplorar el quehacer del Legislativo con su omisión para legislar sobre el particular. El IFE fundamentó su intento fallido de reglamentar el derecho de réplica en el artículo 118 del Cofipe, el cual a la letra dice: "El Consejo General tiene las siguientes atribuciones: a) Aprobar y expedir los reglamentos interiores necesarios para el debido ejercicio de las facultades y atribuciones del Instituto".

Como el propio Cofipe lo señala, el IFE sólo puede expedir reglamentos para desarrollar su operación interna. Al final del día, el IFE no pudo encontrar la cuadratura al círculo. Para evitar reconocer sus propios yerros optó por una salida técnicamente desafortunada. Hizo pero no hizo nada. En efecto, afirma que tutela el derecho de réplica al incluirlo en su Reglamento de Quejas y Denuncias y establece que la protección del derecho referido será hecha a través del procedimiento especial sancionador. Esta iniciativa política quedó desdibujada a un aparato jurídico apenas testimonial. En efecto, no se introdujeron sanciones, procedimientos y al final de cuentas, el IFE apareció como un amigable componedor de esta institución jurídica. ${ }^{13}$

13 http://www.eluniversal.com.mx/nacion/186488.html. 
En el IFE hubo posiciones a favor de regular el derecho de réplica, ${ }^{14}$ y otras técnico-jurídicas que veían impedimentos legales para ese propósito, ${ }^{15}$ organizaciones a favor bajo criterios y argumentos metajurídicos ${ }^{16} \mathrm{e}$ incluso legisladores ${ }^{17}$ que vieron en una resolución del Tribunal Electoral del Poder Judicial de la Federación fundamento legal para regular el derecho de referencia. Esas últimas posiciones no se compadecen con nuestro sistema legal, a pesar de los esfuerzos de la autoridad de IFE por darle algún asidero normativo a esa empresa normativa.

De manera textual, el presidente del IFE, Leonardo Valdés, sostuvo el 23 de junio de 2011 que el IFE intervino para normar el derecho de réplica:

Porque así lo ordenó el Tribunal Electoral del Poder Judicial de la Federación ante la ausencia legislativa de emitir la ley regulatoria del derecho de réplica, el consejo general del Instituto ha iniciado y ha desarrollado un trabajo para que ese derecho que tienen los candidatos, los partidos políticos en el marco del Cofipe, sea también un derecho efectivo. ${ }^{18}$

Esta declaración deja en claro las oportunidades de mejora cognitiva en materia jurídica del presidente del IFE. Es de recordar que el derecho de réplica incluido en la reforma electoral de 2007 forma parte del contenido del primer párrafo del artículo 6o. de la Constitución Política de los Estados Unidos Mexicanos, que a la letra dice: "El derecho de réplica será ejercido en los términos dispuestos por la ley". La naturaleza de cómo fue redactado este enunciado normativo fortalece la postura de que este derecho para su desarrollo está sujeto a lo que técnicamente se denomina reserva de ley; es decir, que para su debido

\footnotetext{
14 http://www.jornada.unam.mx/2011/06/30/politica/017n1polr-orden-del-tepjf/.

15 http://www.mediatelecom.com.mx/index.php?option=com_content \&view $=$ articleerid=11030:el-derecho-de-replica-y-la-facultad-del-ifes catid=92: gobernan za\&Itemid $=100$.

${ }^{16}$ http://www.jornada.unam.mx/2011/06/28/politica/016n2pol.

17 http://www.javiercorral.org/index.php?option=com_contenteview $=$ articlesid $=467$ 9:bienvenida-la-iniciativa-del-ife-de-regular-el-derecho-de-replica-en-materia-electoraljavier-corral-\&catid=162:comunicados-derecho-a-la-informacion\&Itemid=149.

$18 \mathrm{http} / / / w w w$.vanguardia.com.mx/magistradossedeslindanyloscontradiceinstitutofede ral-1034622.html.
} 
y colectivo ejercicio y observancia debe haber previamente la aprobación de una ley en sentido formal, no sólo material. ${ }^{19}$

Como es de conocimiento público sólo el Congreso de la Unión está facultado para expedir leyes y no, por supuesto, el IFE ni ningún otro poder ni organismo autónomo. No sólo se trata de un resultado de la división constitucional de poderes, sino de la primacía de la Constitución que establece las reglas jurídicas a las que deben sujetarse gobernantes y gobernados.

Por supuesto, si el modelo actual no es el deseable para algunos, la vía es que a través de los mecanismos que el sistema normativo establece se hagan las propuestas de reforma normativa que se considere pertinente $y$, en su caso, sean valoradas por el Poder Legislativo para que determine lo conducente. Lo que no es dable, empero, es dejar de lado el diseño institucional vigente para llevar a cabo tareas que justificables y entendibles desde perspectivas sociológicas o ideológicas no están fundadas ni motivadas con arreglo a derecho. Uno de los elementos básicos de todo Estado de derecho es el principio de legalidad que brinda certidumbre a la sociedad. Este principio establece que la autoridad sólo puede desplegar aquellas conductas que expresamente le atribuye el marco legal.

El IFE carece de toda atribución legislativa y menos todavía para normar un derecho fundamental previsto en la Constitución. La Suprema Corte de Justicia de la Nación ha resuelto con carácter de jurisprudencia que:

El principio de la división funcional de poderes se desarrolla constitucionalmente mediante la atribución de competencias expresas conferidas a los órganos superiores del Estado; en ese sentido, el principio limita la actuación de las autoridades, lo que significa que todo aquello para lo que no están expresamente facultadas se encuentra prohibido y que sólo puede realizar los actos que el ordenamiento jurídico prevé y, en particular, sobre las bases que la Constitución Política de los Estados Unidos Mexicanos. ${ }^{20}$

Por tal razón si el IFE hubiera proseguido con llevar a cabo las conductas prohibidas por la Constitución hubiera podido incurrir en dos

19 Cfr. Amparo en revisión 1948/94. Proveedora de Señales y Dispositivos para Tránsito A.A. de C.V. 30 de agosto de 1995.

${ }^{20}$ Jurisprudencia 9/2006, controversia constitucional 14/2005. 
supuestos: $a$ ) por un lado las normas creadas relativas al derecho de réplica estarán afectadas de nulidad; en otras palabras, se considerarán como no puestas o inexistentes debido a que la autoridad que las emite (el IFE) no tiene atribuciones para tal efecto, y $b$ ) por otro, los consejeros y con mayor razón el secretario ejecutivo del IFE hubieran abierto con estas conductas la puerta para que se les pudiera fincar responsabilidades políticas y administrativas como sanción por llevar a cabo conductas inconstitucionales en los términos de lo dispuesto por el artículo 108 de la carta magna.

Hay que dejar claro que el Poder Judicial de la Federación no puede suplir las atribuciones exclusivas del Poder Legislativo a efecto de ordenar en sus términos que el IFE reglamente, norme o regule el derecho de réplica. Ante la presencia de lo que técnicamente se denomina omisión legislativa que supone que el Congreso se abstiene de ejercer sus atribuciones para legislar hay dos tipos: a) la omisión absoluta, que significa que no ha legislado nada de la materia que tiene atribuciones para legislar, y $b$ ) la omisión relativa, que significa que al legislar sobre alguna materia lo ha hecho insatisfactoriamente de acuerdo a lo que establece la Constitución. Por lo que concierne al derecho de réplica el Congreso de la Unión ha incurrido en una omisión legislativa absoluta que es lamentable desde el punto de vista sociológico, pero jurídicamente no tiene hasta ahora consecuencias a la actualización de la conducta contraria a la establecida como debida por la norma.

Por lo anterior, el Poder Judicial carece de atribuciones para legislar o para ordenar que se legisle por omisión absoluta. Así, a mayor abundamiento, lo ha entendido la Suprema Corte de Justicia de la Nación en diversas ocasiones. Por ejemplo, ha señalado que las omisiones absolutas:

Son aquellas en las que dichos órganos (legislativos) pueden decidir si las ejercen o no y el momento en que lo harán; de manera que esta competencia en sentido estricto no implica una obligación, sino la posibilidad establecida en el ordenamiento jurídico de crear, modificar o suprimir normas generales, es decir, los órganos legislativos cuentan con la potestad de decidir libremente si crean determinada norma jurídica y el momento en que lo harán. ${ }^{21}$

${ }^{21}$ Jurisprudencia 10/2006, controversia constitucional 14/2005. 
Por si lo anterior no fuera suficiente para señalar la indebida intervención del IFE en el derecho de réplica, la propia presidenta del Tribunal Electoral del Poder Judicial de la Federación, María del Carmen Alanís, precisó que la sentencia que a decir del IFE sirvió de sustento a su decisión para normar el derecho de réplica "es una resolución en un sentido que no es jurisprudencia. Es un criterio relevante, un precedente del Tribunal, pero lo más importante es que nosotros no ordenamos reglamentar y la resolución es pública". ${ }^{22}$

El derecho de réplica es un derecho fundamental en México, pero la impericia legislativa de diputados y senadores, las presiones de los medios televisivos y el desconocimiento de la ley en la materia por parte del árbitro electoral constituyen un complejo entramado en donde se ha podido avanzar sólo en la parte dogmática constitucional. No se han podido, empero, dar pasos hacia el desarrollo legal de esta figura jurídica que es necesaria para generar mecanismos mínimos de contrapeso social en los medios que ahora en el país son inexistentes.

\section{Bibliografía}

Ballester, Eliel C., Derecho de respuesta. Réplica. Rectificación, Buenos Aires, Astrea, 1987.

Fiss, Owen, The Theory of Free Speech, Harvard University Press, 1996. Godoy, Antonio, El derecho de la televisión sin fronteras, Alicante, Aguaclara, 1995.

IsLAS L., Jorge, "El derecho de réplica y la vida privada", en Jiménez, Armando Alfonso (coord.), Responsabilidad social, autorregulación y legislación en radio y televisión, México, UNAM, 2002.

Laguna de Paz, José Carlos, Régimen jurídico de la televisión privada, Madrid, Marcial Pons, 1994.

Molinero, César, Teoría y fuentes del derecho de la información, 2a. ed., Barcelona, EUB, 1995.

Rebollo Delgado, Lucrecia, "El derecho de rectificación", en Tenorio J., Pedro y Fernández Miranda, Carmen (coords.), El derecho de la información, Madrid, UNED ediciones, 2001.

${ }^{22}$ www.vanguardia.com. $m x$, nota citada. 
Rivera, Julio César, La constitucionalidad del derecho de rectificación o respuesta, Buenos Aires, Rubinzal-Culzoni, 2004.

UPRIMNY, Rodrigo et al., Libertad de prensa y derechos fundamentales, Bogotá, Andiarios-Fundación Konrad Adenauer, 2006.

Villalobos Quirós, Enrique, "El derecho de rectificación o respuesta”, en Villanueva, Ernesto (coord.), Diccionario de derecho de la información, México, Porrúa.

Villanueva, Ernesto, Derecho de la información, México, Miguel Ángel Porrúa, 2006. 